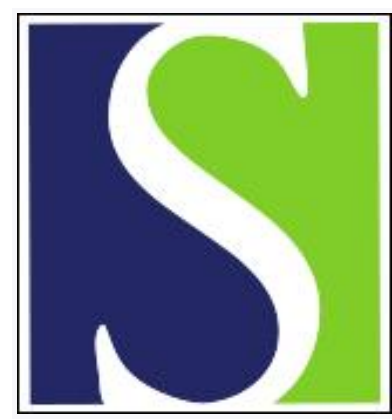

Scand J Work Environ Health 2002;28(4):222-231

https://doi.org/10.5271/sjweh.669

Issue date: Aug 2002

High physical and psychosocial load at work and sickness absence due to neck pain

by Ariëns GAM, Bongers PM, Hoogendoorn WE, van der Wal G, van Mechelen W

Affiliation: Bocy@Work, Research Center Physical Activity, Work and Health TNO-VU, EMGO Institute, Van der Boechorstasraat 7, NL-1081

BT Amsterdam, Netherlands. g.ariens.emgo@med.vu.nl

Refers to the following texts of the Journal: 2000;26(1):7-19

2001;27(4):258-267

The following articles refer to this text: 2004;30(1):56-63;

2010;36(1):34-41; 2011;37(6):512-524; 2013;39(5):468-476

Key terms: cervical spine; longitudinal study; neck pain; physical load; prospective cohort study; psychosocial load; risk factor; sick leave; sickness absence; work; work-related neck pain; work-related physical load; work-related psychosocial load

This article in PubMed: www.ncbi.nlm.nih.gov/pubmed/12199423 


\title{
High physical and psychosocial load at work and sickness absence due to neck pain
}

\author{
by Geertje AM Ariëns, PhD, 1, 2 Paulien M Bongers, PhD,1,3 Wilhelmina E Hoogendoorn, PhD,2,3 \\ Gerrit van der Wal, PhD, ${ }^{2}$ Willem van Mechelen, $P h D^{1,2}$
}

\begin{abstract}
Ariëns GAM, Bongers PM, Hoogendoorn WE, van der Wal G, van Mechelen W. High physical and psychosocial load at work and sickness absence due to neck pain. Scand J Work Environ Health 2002;28(4):222-231.

Objectives This study investigates the relationship between physical and psychosocial load at work and sickness absence due to neck pain.

Methods A prospective cohort study with a follow-up period of 3 years (1994-1998) was performed among a working population. At the beginning of the study, physical load at work was quantified by means of video recordings. Work-related psychosocial variables were measured by means of the Job Content Questionnaire. The frequency of sickness absence due to neck pain with a minimal duration of 3 days was assessed on the basis of company registrations during the follow-up period. Altogether 758 workers were included in the analyses. Possible confounding by individual characteristics, physical load, and psychosocial load was studied.

Results Work-related neck flexion and neck rotation, low decision authority, and medium skill discretion showed statistically significant increased risks for sickness absence due to neck pain (adjusted rate ratios ranging from 1.6 to 4.2). High quantitative job demands, low skill discretion, and low job security showed nonsignificant increased risks for sickness absence due to neck pain (adjusted rate ratios of 2.0, 1.6 and 1.7, respectively). Work-related sitting, conflicting job demands, supervisor support, and co-worker support did not increase sickness absence due to neck pain.

Conclusions Work-related neck flexion, neck rotation, low decision authority, and medium skill discretion are risk factors for sickness absence due to neck pain. There are indications that high job demands, low skill discretion, and low job security are also risk factors for sickness absence due to neck pain.
\end{abstract}

Key terms cervical spine, longitudinal, risk factors, prospective cohort study, sick leave, work-related.

Neck pain is a major health problem in modern society. One-year prevalences of neck pain in occupational settings have shown values varying from $6 \%$ to $76 \%$, with higher values for female workers (1). In The Netherlands, a 1-year prevalence figure of $31.4 \%$ was found in 1998 (2). Data on sickness absence due to neck pain are scarce. In their longitudinal study, Burdorf et al (3) reported that the proportion of workers that experienced at least one period of sickness absence due to neck or shoulder pain during a follow-up period of two years was $17 \%$. Waersted \& Westgaard (4) reported that, for full-time workers, long-term sickness absence due to neck and upper-limb disorders was $2.2 \%$ of the total number of days employed, and, for part-time workers, the corresponding value was $1.8 \%$. Neither study looked at neck-specific sickness absence exclusively. Borghouts et al (5) estimated the total costs of neck pain in The Netherlands in 1996 to be USD 868 million. The total number of sick days related to neck pain was estimated to be 1.4 million, with a total cost of USD 185.4 million.

Neck pain is assumed to be of multifactorial origin, with the implication that several risk factors can contribute to its development. According to the results of

3 TNO Work and Employment, Hoofddorp, The Netherlands.

Reprint requests to: Dr Geertje AM Ariëns, Body@Work, Research Center Physical Activity, Work and Health TNO-VU, EMGO Institute, Van der Boechorststraat 7, NL-1081 BT Amsterdam, The Netherlands. [E-mail: g.ariens.emgo@med.vu.nl] 
two systematic reviews on physical and psychosocial risk factors for neck pain, there seems to be evidence that neck flexion and sitting are physical risk factors for neck pain, whereas high quantitative job demands, low authority over decisions, low skill discretion, and poor social support by colleagues are important work-related psychosocial risk factors for neck pain $(6,7)$. Whether these and other work-related variables are also related to sickness absence due to neck pain is unclear, because literature on the relationship between work-related physical and psychosocial variables and sickness absence due to neck pain is scarce.

In their literature review, Ganster \& Schaubroeck (8) formulated recommendations regarding future research in the field of work stress and employee health. They recommended longitudinal designs and the use of "hard" outcome measures.

In our present study, we investigated what level of physical exposure (ie, neck flexion, neck rotation, and sitting) and what level of psychosocial exposure (ie, quantitative job demands, conflicting job demands, skill discretion, decision authority, supervisor support, coworker support, and job security) leads to an increased risk of sickness absence due to neck pain. Data from a prospective cohort study in an occupational setting were used. Company-registered sickness absence information was used as the outcome measure.

\section{Subjects and methods}

In 1994, a study on musculoskeletal disorders, absenteeism, stress and health (SMASH), a large prospective cohort study with a follow-up period of 3 years, was initiated among a working population. The main purpose of SMASH was to determine risk factors for musculoskeletal disorders, with focus on back, neck, and shoulder disorders. Approximately 1800 male and female workers from 34 companies participated in SMASH. The participating companies were located throughout The Netherlands, and they included various industrial and service branches, which resulted in a study population of workers with a wide range of physical and mental workloads. Extensive information on SMASH can be found elsewhere (9-13).

\section{Study population}

Altogether 1789 of the 2064 workers who were invited to participate in SMASH filled out the questionnaire at the beginning of the study $(87 \%)$. In order to be included in this particular analysis, participants had to meet the following criteria at the beginning of the study: (i) no other paid job for any substantial amount of time, (ii) no work disability payment due to neck pain in the previous 12 months, (iii) at least 20 hours of work a week, (iv) at least 1 year in current job, (v) no sickness absence due to neck pain in the 3 months prior to the beginning of the study, (vi) registration of sickness absence covered at least a period of half a year after the time the baseline measurements took place. After these selection criteria were applied, 1025 workers were eligible for inclusion in the analysis.

\section{Work-related physical variables}

At the beginning of the study, work-related physical load was quantified by means of video recordings and force measurements at the workplace and subsequent observation and analysis of these video recordings. Four 10- or 14-minute video recordings of each participant were taken randomly during a workday. All the participants were assigned to groups of workers with similar tasks, based on onsite inspection of the work. Video recordings of one-fourth of the workers in each of these groups of workers were subsequently observed and analyzed for relevant measures. Multimoment video observations (every 15 seconds) were made of head inclination (in three categories: 0-20, 20-45 and >45 degrees out of the neutral position) and head rotation (in two categories: 0-45 and >45 degrees out of the neutral position). Continuous video observations were made of work in a sitting position. Based on these observations, the following four work-related physical variables were calculated: (i) the percentage of the worktime with the neck flexed a minimum of 20 degrees, (ii) the percentage of the worktime with the neck flexed a minimum of 45 degrees, (iii) the percentage of the worktime with the neck rotated a minimum of 45 degrees, and (iv) the percentage of the worktime sitting. The mean values were calculated for these physical variables on the basis of the observed video tapes of workers within each group. Each worker within a group was then allocated the mean value for each of the four previously mentioned physical variables.

\section{Work-related psychosocial variables}

At the beginning of the study, information on work-related psychosocial variables was collected by means of the Job Content Questionnaire (14). This questionnaire measures the dimensions of the widely used demandcontrol-support model $(15,16)$. On a 4-point scale (totally disagree, disagree, agree, totally agree) workers were asked to assess certain aspects of their work. Various items of the questionnaire were combined into dimensions as proposed by Karasek (15) [ie, quantitative job demands (5 items), skill discretion (5 items), decision authority (3 items), supervisor support (4 items), and co-worker support (4 items)]. The construction of these dimensions for the data from SMASH has been described by De Jonge et al (13). Single items 
of the questionnaire were used for assessing job security ("I feel secure about my job") and conflicting job demands ("I don't get conflicting assignments from others").

\section{Registration of sickness absence due to neck pain}

Sickness absence was registered in a standardized way from the beginning of the study until December 1997. The participating companies registered the exact date of the onset and end of each period of sickness absence and wrote down the reasons for it. The occupational health physician of the occupational health service of each company checked the reasons for sickness absence and added, if possible, the diagnosis code to each period of sickness absence, using the GDS code system (17). This code system is an adapted Dutch version of the International Classification of Diseases (ICD) (18). From the registration, information was derived on the frequency of sickness absence due to neck pain with a minimal duration of 3 days. Table 1 presents the codes that were defined as neck-specific reasons for sickness absence. In addition, the duration of the registration period was calculated in person-months.

\section{Potential confounders}

Potential confounders were measured at the beginning of the study. Information on other work-related physical factors was derived from the video recordings and from a self-administered questionnaire (19). Furthermore, by means of a questionnaire, data were collected on nonwork-related physical factors $(19,20)$ and individual characteristics $(21,22)$. The work-related physical and psychosocial variables were also considered to be potential confounders for each other. The potential confounders are listed in the appendix.

Table 1. Gedifferentieerd diagnosecode-systeem (GDS codes) that were defined to be neck-specific reasons for sickness absence.

\begin{tabular}{|c|c|}
\hline Code & Description of code \\
\hline 722.0 & $\begin{array}{l}\text { Discopathy, multiple sites, of which the neck region is one, no } \\
\text { root symptoms }\end{array}$ \\
\hline 722.1 & Discopathy, cervical, no root symptoms \\
\hline 722.3 & $\begin{array}{l}\text { Discopathy, multiple sites, of which the neck region is one, } \\
\text { radiating pain, no herniated disc }\end{array}$ \\
\hline 722.4 & Discopathy, cervical, radiating pain, no herniated disc \\
\hline 722.6 & $\begin{array}{l}\text { Herniated disc, multiple sites, of which the neck region is one, } \\
\text { with or without root symptoms }\end{array}$ \\
\hline 722.7 & Herniated disc, cervical, with or without root symptoms \\
\hline 722.9 & Discopathy, not described further \\
\hline 723.1 & Neck pain, neck myalgia (no spine abnormalities) \\
\hline 723.2 & Brachialgia, accompanied by neck pain \\
\hline
\end{tabular}

\section{Statistics}

The Poisson regression technique was used to model the relationship between work-related physical and psychosocial variables and the frequency of sickness absence due to neck pain with a minimal duration of 3 days (hereafter referred to as sickness absence due to neck pain), and it resulted in the calculation of a rate ratio (RR) and its corresponding 95\% confidence interval (95\% CI) (23). The analyses were performed with the SAS statistical package (24).

The work-related physical variables derived from the video recordings were divided into several small categories. Categories showing similar effect estimates were combined into broader categories and resulted in the following categorization of the four work-related physical variables: the percentage of worktime with the neck flexed a minimum of 20 degrees in three categories ( $<30 \%$ of the worktime, $30-40 \%$ of the worktime, $>40 \%$ of the worktime); the percentage of worktime with the neck flexed a minimum of 45 degrees in two categories ( $<5 \%$ of the worktime, $>5 \%$ of the worktime); the percentage of worktime with the neck rotated a minimum of 45 degrees in two categories ( $<25 \%$ of the worktime, $>25 \%$ of the worktime); the percentage of worktime sitting in four categories ( $<1 \%$ of the worktime, $1-50 \%$ of the worktime, $50-95 \%$ of the worktime, $>95 \%$ of the worktime).

A comparable strategy was used to categorize the work-related psychosocial dimensions quantitative job demands, decision authority, skill discretion, co-worker support, and supervisor support, which were all divided into three categories (low, medium, high). The two work-related psychosocial variables job security and conflicting job demands were divided into two categories [agree (totally), disagree (totally)].

First, univariate analyses of the relationship between each of the work-related physical and psychosocial variables and the frequency of sickness absence due to neck pain were performed. Second, univariate analyses were performed to test the relationship between each potential confounder and the frequency of sickness absence due to neck pain. Potential confounders associated with sickness absence due to neck pain with a P-value of $<0.25$ were considered probable confounders (25). Third, for potential confounders with a univariate P-value of $<0.25$, the actual confounding effect on the estimated rate ratio of each work-related physical and psychosocial variable was examined. Therefore, the estimated rate ratio for each work-related physical and psychosocial variable resulting from an analysis in which one work-related physical or psychosocial variable and one confounder were combined was compared with the crude rate ratio of this work-related physical or psychosocial variable. If the change in this rate ratio 
was $\geq 10 \%$, the potential confounder was considered to be a real confounder in this dataset. By checking the correlations, we verified the interrelationships between the work-related physical and psychosocial variables and the confounders to avoid colinearity. Finally, in the last step of the analysis, a multivariate model was constructed for each work-related physical and psychosocial variable, and in this model all the confounders determined during the previous steps of the analysis were included. Age and gender were selected a priori as confounders and included in all multivariate analyses.

Finally, the effect was studied of neck pain at the beginning of the study on the relationship between work-related physical and psychosocial variables and sickness absence due to neck pain. For this purpose, the variable "regular or prolonged neck pain in the 12 months prior to the beginning of the study" was univariately related to sickness absence due to neck pain, and the variable was added to each multivariate model.

A total of 1025 subjects met the inclusion criteria. For 267 subjects (26\%) data on reasons for sickness absence due to neck pain were incomplete.

In the group of workers with missing data on the reasons for sickness absence, fewer worked with the neck flexed $>20$ degrees, or with the neck rotated $>45$ degrees, for a high percentage of their worktime $(\mathrm{P}<0.05)$. In addition fewer workers in the group with missing data were sitting for a high percentage of their worktime $(\mathrm{P}<0.05)$. In contrast, relatively more workers among those with missing data worked with their neck flexed $>45$ degrees for a high percentage of their worktime $(\mathrm{P}<0.05)$.

No difference was found in the distributions of the work-related psychosocial variables quantitative job demands, conflicting job demands, and co-worker support between those included in this study and those with missing data on the reasons for sickness absence. For the other work-related psychosocial variables (ie, decision authority, skill discretion, supervisor support and job security) a statistically significant difference $(\mathrm{P}<0.05)$ was found between the two groups. In the group of workers with missing data, the percentage of workers in the high-risk categories was higher.

\section{Results}

\section{Descriptive information on the study population}

Of the 758 workers included in this analysis, 567 $(74.8 \%)$ were men. The mean age of the study population was 36.3 (SD 8.8) years. The mean duration of employment in the current job was 7.8 (SD 7.7) years, and the mean number of workhours per week was 38.9

(SD 4.2) hours. The baseline distribution of the workrelated physical and psychosocial variables is presented in table 2.

During the follow-up period, a total of 36 workers $(4.7 \%)$ had been absent from work due to neck pain,

Table 2. Distribution of the work-related physical and psychosocial variables at the beginning of the study.

\begin{tabular}{|c|c|c|}
\hline \multirow[t]{2}{*}{ Variable } & \multicolumn{2}{|c|}{ Distribution } \\
\hline & $\mathrm{N}$ & $\%$ \\
\hline \multicolumn{3}{|c|}{$\begin{array}{l}\text { Percentage of worktime with neck flexed } \\
\geq 20 \text { degrees }\end{array}$} \\
\hline$<30 \%$ & 230 & 31.6 \\
\hline $30-40 \%$ & 270 & 37.1 \\
\hline$>40 \%$ & 227 & 31.2 \\
\hline \multicolumn{3}{|c|}{$\begin{array}{l}\text { Percentage of the worktime with neck flexed } \\
\geq 45 \text { degrees }\end{array}$} \\
\hline$<5 \%$ & 600 & 82.5 \\
\hline$>5 \%$ & 127 & 17.5 \\
\hline \multicolumn{3}{|c|}{$\begin{array}{l}\text { Percentage of the worktime with neck } \\
\text { rotated } \geq 45 \text { degrees }\end{array}$} \\
\hline$<25 \%$ & 602 & 82.8 \\
\hline$>25 \%$ & 125 & 17.2 \\
\hline \multicolumn{3}{|c|}{$\begin{array}{l}\text { Percentage of the worktime in a sitting } \\
\text { position }\end{array}$} \\
\hline$<1 \%$ & 152 & 20.9 \\
\hline $1-50 \%$ & 243 & 33.4 \\
\hline $50-95 \%$ & 274 & 37.3 \\
\hline$>95 \%$ & 58 & 8.0 \\
\hline \multicolumn{3}{|c|}{$\begin{array}{l}\text { Quantitative job demands (mean 13.0, SD 2.3, } \\
\text { range 5-20) }\end{array}$} \\
\hline Low (score <14) & 464 & 61.9 \\
\hline Medium (score 14-17) & 232 & 30.9 \\
\hline High (score $>17$ ) & 54 & 7.2 \\
\hline \multicolumn{3}{|l|}{ Conflicting job demands } \\
\hline Disagree (totally) & 493 & 66.0 \\
\hline Agree (totally) & 254 & 34.0 \\
\hline \multicolumn{3}{|c|}{$\begin{array}{l}\text { Decision authority (mean } 8.3 \text {, SD } 1.7 \text {, } \\
\text { range } 3-12 \text { ) }\end{array}$} \\
\hline High (score >8) & 338 & 45.7 \\
\hline Medium (score 7-8) & 290 & 38.3 \\
\hline Low (score $<7$ ) & 111 & 15.0 \\
\hline \multicolumn{3}{|c|}{$\begin{array}{l}\text { Skill discretion (mean 14.6, SD 2.6, } \\
\text { range 5-20) }\end{array}$} \\
\hline High $($ score $>14$ ) & 432 & 57.5 \\
\hline Medium (score 14) & 113 & 15.0 \\
\hline Low (score <14) & 206 & 27.4 \\
\hline \multicolumn{3}{|c|}{$\begin{array}{l}\text { Co-worker support (mean 12.0, SD 1.6, } \\
\text { range 4-16) }\end{array}$} \\
\hline High (score >14) & 69 & 9.2 \\
\hline Medium (score 11-14) & 591 & 79.0 \\
\hline Low $($ score $<11)$ & 88 & 11.8 \\
\hline \multicolumn{3}{|c|}{$\begin{array}{l}\text { Supervisory support (mean 11.1, SD 2.1, } \\
\text { range 4-16) }\end{array}$} \\
\hline High $($ score $>11)$ & 533 & 71.1 \\
\hline Medium (score 9-11) & 128 & 17.1 \\
\hline Low (score $<9$ ) & 89 & 11.9 \\
\hline \multicolumn{3}{|l|}{ Job security } \\
\hline Agree (totally) & 634 & 83.6 \\
\hline Disagree (totally) & 117 & 15.4 \\
\hline
\end{tabular}


5 of whom were absent from work twice due to neck pain twice during the follow-up period, and one subject was absent from work three times due to neck pain. The mean duration of sickness absence was 17 days, and the median was 11 days. Furthermore, the duration of the sickness absence was 8 days or longer for 20 of these 36 workers. Each worker was followed for a maximum of 44 months. The mean time until sickness absence due to neck pain was 17 (range 1-44) months.

The potential confounders are listed in the appendix. The variables marked with an asterisk were found to be univariately associated with sickness absence due to neck pain, with a $\mathrm{P}$-value of $<0.25$.

The percentage of the worktime with a minimum of 60 degrees of upper arm elevation and work with video display terminals correlated with a number of work-related physical and psychosocial variables (Pearson's correlation coefficients ranging from -0.65 to 0.62 ). Skill discretion and decision authority were also correlated (Pearson's correlation coefficient 0.47 ). To avoid colinearity, we decided not to combine these variables into one single multivariate analysis.

\section{Work-related physical variables and sickness absence due to neck pain}

The results of the univariate and multivariate analyses of the association between the work-related physical variables and sickness absence due to neck pain are presented in table 3 . Compared with the reference category, workers with the neck flexed a minimum of 20 degrees for more than $40 \%$ of the worktime had a statistically significant increased crude and adjusted rate ratio of 3.4 and 4.2 , respectively, for sickness absence due to neck pain. In addition, workers with the neck flexed a minimum of 45 degrees for $>5 \%$ of the worktime had an increased crude and adjusted rate ratio of 2.2 and 2.8, respectively. The crude and adjusted rate ratio for workers with the neck rotated a minimum of 45 degrees for $>25 \%$ of their worktime was 1.9 and 2.8 , respectively.

For the fourth work-related physical factor (ie, the percentage of worktime sitting) a statistically significant rate ratio of $<1$ was found for the workers who sat for $1-50 \%$ of their worktime (adjusted RR 0.3 ). The adjusted rate ratio for sitting for 50-95\% of the worktime was still decreased, but no longer statistically significant. The effect disappeared for the group of subjects who were sitting for more than $95 \%$ of their worktime.

The most important confounders in the analysis of the relationship between work-related physical variables and sickness absence due to neck pain were other physical variables. These were more important than the psychosocial variables or individual characteristics.

\section{Work-related psychosocial variables and sickness absence due to neck pain}

The results of the univariate and multivariate analyses of the associations between the work-related psychosocial variables and sickness absence due to neck pain are also presented in table 3 . The workers who scored relatively low on decision authority showed a statistically significant increased crude and adjusted rate ratio of 4.4 and 3.7, respectively. Moreover, the rate ratio for medium decision authority was also statistically significantly increased. Medium skill discretion was statistically significantly related to sickness absence due to neck pain (crude RR 2.7, adjusted RR 2.6). The crude and adjusted rate ratios for low skill discretion were also increased, but not statistically significant. Furthermore, increased risks were found for high quantitative job demands and low job security in relation to sickness absence due to neck pain. However, the adjusted rate ratios were not statistically significant for these variables. Finally, no relationship was found between conflicting job demands, supervisory support, or co-worker support and sickness absence due to neck pain.

The most important confounders in the analysis of the relationship between work-related psychosocial variables and sickness absence due to neck pain were other psychosocial variables. These variables were more important than the physical variables or individual characteristics.

\section{Neck pain at the beginning of the study}

Seventeen percent of the workers reported that they had had neck pain in the 12 months prior to the beginning of the study. Neck pain in the 12 months prior to the beginning of the study was univariately associated with sickness absence due to neck pain, with a rate ratio of 2.66 (95\% CI 1.40-5.08). However, comparable adjusted rate ratios were found for the relationship between the work-related physical and psychosocial variables and sickness absence due to neck pain when the variable "neck pain in the 12 months prior to the beginning of the study" was added to the multivariate model of each of the work-related physical and psychosocial variables (data not shown).

\section{Discussion}

The objective of our study was to investigate the relationship between work-related physical and psychosocial variables and sickness absence due to neck pain. We believe that this is the first prospective cohort study in which this relationship has been studied specifically for sickness absence due to neck pain. Moreover, the study 
Table 3. Results of the univariate and multivariate analyses of the association between work-related physical and psychosocial variables and sickness absence due to neck pain with a minimal duration of 3 days. ( $\mathrm{RR}=$ rate ratio, $95 \% \mathrm{Cl}=95 \%$ confidence interval)

\begin{tabular}{|c|c|c|c|c|}
\hline \multirow[t]{2}{*}{ Work-related variable } & \multicolumn{2}{|c|}{ Crude $^{a}$} & \multicolumn{2}{|c|}{ Adjusted $^{b}$} \\
\hline & $\mathrm{RR}$ & $95 \% \mathrm{Cl}$ & $\mathrm{RR}$ & $95 \% \mathrm{Cl}$ \\
\hline \multicolumn{5}{|l|}{ Neck flexion $\geq 20$ degrees } \\
\hline$<30 \%$ of worktime & 1.00 & $\cdot$ & $1.00^{c}$ & $\cdot$ \\
\hline $30-40 \%$ of worktime & 1.56 & $0.58-4.23$ & 2.65 & $0.88-7.97$ \\
\hline$>40 \%$ of worktime & 3.37 & $1.35-8.39^{*}$ & 4.19 & $1.50-11.69^{*}$ \\
\hline \multicolumn{5}{|l|}{ Neck flexion $\geq 45$ degrees } \\
\hline$<5 \%$ of worktime & 1.00 & $\cdot$ & $1.00^{d}$ & $\cdot$ \\
\hline$>5 \%$ of worktime & 2.24 & $1.12-4.45^{\star}$ & 2.76 & $1.27-5.99^{\star}$ \\
\hline \multicolumn{5}{|l|}{ Neck rotation $\geq 45$ degrees } \\
\hline$<25 \%$ of worktime & 1.00 & $\cdot$ & $1.00^{e}$ & $\cdot$ \\
\hline$>25 \%$ of worktime & 1.89 & $0.92-3.91$ & 2.81 & $1.29-6.09^{\star}$ \\
\hline \multicolumn{5}{|l|}{ Sitting } \\
\hline$<1 \%$ of worktime & 1.00 & . & $1.00^{\dagger}$ & . \\
\hline $1-50 \%$ of worktime & 0.38 & $0.17-0.87^{\star}$ & 0.32 & $0.13-0.76^{\star}$ \\
\hline $50-95 \%$ of worktime & 0.28 & $0.11-0.68^{*}$ & 0.38 & $0.12-1.16$ \\
\hline$>95 \%$ of worktime & 1.00 & $0.39-2.57$ & 1.70 & $0.46-6.31$ \\
\hline \multicolumn{5}{|l|}{ Quantitative job demands } \\
\hline Low & 1.00 & $\cdot$ & $1.00^{g}$ & $\cdot$ \\
\hline Medium & 0.78 & $0.37-1.61$ & 0.73 & $0.35-1.53$ \\
\hline High & 2.43 & $1.05-5.59^{\star}$ & 1.96 & $0.83-4.62$ \\
\hline \multicolumn{5}{|l|}{ Conflicting job demands } \\
\hline Disagree (totally) & 1.00 & . & $1.00^{\mathrm{h}}$ & . \\
\hline Agree (totally) & 0.95 & $0.50-1.80$ & 0.96 & $0.51-1.83$ \\
\hline \multicolumn{5}{|l|}{ Decision authority } \\
\hline High & 1.00 & $\cdot$ & $1.00^{i}$ & $\cdot$ \\
\hline Medium & 3.47 & $1.56-7.73^{\star}$ & 3.03 & $1.35-6.82^{\star}$ \\
\hline Low & 4.36 & $1.75-10.83^{*}$ & 3.66 & $1.44-9.26^{\star}$ \\
\hline \multicolumn{5}{|l|}{ Skill discretion } \\
\hline High & 1.00 & . & $1.00^{j}$ & . \\
\hline Medium & 2.70 & $1.17-6.24^{\star}$ & 2.56 & $1.08-6.04^{\star}$ \\
\hline Low & 2.08 & $0.99-4.36$ & 1.64 & $0.73-3.69$ \\
\hline \multicolumn{5}{|l|}{ Co-worker support } \\
\hline High & 1.00 & $\cdot$ & $1.00^{k}$ & $\cdot$ \\
\hline Medium & 1.16 & $0.36-3.81$ & 0.92 & $0.26-3.18$ \\
\hline Low & 0.79 & $0.16-3.91$ & 0.51 & $0.10-2.70$ \\
\hline \multicolumn{5}{|l|}{ Supervisory support } \\
\hline High & 1.00 & . & $1.00^{\prime}$ & $\cdot$ \\
\hline Medium & 1.91 & $0.96-3.79$ & 1.62 & $0.81-3.24$ \\
\hline Low & 1.23 & $0.47-4.24$ & 0.96 & $0.35-2.60$ \\
\hline \multicolumn{5}{|l|}{ Job security } \\
\hline Agree (totally) & 1.00 & . & $1.00 \mathrm{~m}$ & . \\
\hline Disagree (totally) & 1.98 & $0.96-4.09$ & 1.70 & $0.80-3.60$ \\
\hline
\end{tabular}

a Crude rate ratio and $95 \% \mathrm{Cl}$ from the Poisson regression analysis.

b Adjusted rate ratio and $95 \% \mathrm{Cl}$ from the Poisson regression analysis.

c Adjusted for gender, age, neck rotation of $\geq 45$ degrees, sitting posture, decision authority, skill discretion, leisure-time activities with hands above shoulder level, and sports participation.

d Adjusted for gender, age, sitting posture, and leisure-time activities with hands above shoulder level.

e Adjusted for gender, age, neck flexion of $\geq 45$ degrees, sitting posture, and sports participation.

f Adjusted for gender, age, neck flexion of $\geq 45$ degrees, neck rotation of $\geq 45$ degrees, decision authority, skill discretion, frequent flexion or rotation of the upper part of the body during leisure time, driving a vehicle during leisure time, sports participation, and coping (active problem solving).

${ }^{9}$ Adjusted for gender, age, and decision authority.

${ }^{\mathrm{h}}$ Adjusted for gender and age.

Adjusted for gender, age, sports participation, and coping (active problem solving).

i Adjusted for gender, age, sitting posture, and coping (active problem solving).

${ }^{k}$ Adjusted for gender, age, neck flexion of $\geq 20$ degrees, neck rotation of $\geq 45$ degrees, sitting posture, decision authority, skill discretion, and supervisory support.

I Adjusted for gender, age, quantitative job demands, and decision authority.

$m$ Adjusted for gender, age, neck flexion of $\geq 20$ degrees, and decision authority.

${ }^{*} \mathrm{P}<0.05$. 
is based on sickness absence information registered by the participating companies and on quantified physical exposure data. The potential confounding effects of various important work-related and nonwork-related physical and psychosocial variables and individual characteristics were taken into account.

\section{Summary of the results and comparison with the literature}

Comparison of the results of our study with those of studies described in the literature is difficult, since there are hardly any studies that have investigated the relationship between work-related risk factors and neck-specific sickness absence. Many studies have investigated the relationship between work-related physical and psychosocial factors and sickness absence due to a broader range of reasons $(15,26-31)$.

Furthermore, the results of this study can be compared with those of two other studies in which the relationship is described of the same work-related physical and psychosocial variables and the occurrence of neck pain, based on the same dataset $(9,10)$. However, this comparison is hampered by several points, the most important being the difference in the number of subjects included in the analyses, which leads to an adaptation in the categorization of the exposure variables. Another point that hampers the comparison is a more theoretical one. Neck pain can be seen as a health problem. Sickness absence includes more than just a health problem. It can be seen as an integrated measure of physical, psychological, and social functioning in studies of working populations (32). It is therefore reasonable to expect that there are also other risk factors involved in the prediction of neck pain and sickness absence due to neck pain.

Earlier analyses with the same dataset indicated that neck flexion was related to the occurrence of neck pain (9). In agreement with this finding, our study showed that neck flexion was also related to sickness absence due to neck pain. Although not related to the occurrence of neck pain (9), neck rotation proved, in our study, to be related to sickness absence due to neck pain.

Work-related sitting was not associated with an increased risk of sickness absence due to neck pain. This finding does not agree with the results of the study carried out by Ekberg \& Wildhagen (26), who concluded that uncomfortable sitting was a major predictor of days of sick leave due to neck and shoulder disorders. Earlier analyses of the data on the relationship between workrelated physical variables and the occurrence of neck pain showed that prolonged sitting (more than $95 \%$ of worktime) was a risk factor for neck pain (9). In contrast, prolonged sitting was not related to sickness ab- sence due to neck pain. Apparently, subjects who sit for a substantial amount of their worktime report neck pain more often, but are not more often absent from work due to their neck pain.

Our study showed that workers involved in jobs with low decision authority appeared to have an increased risk of sickness absence due to neck pain. Several authors have reported comparable findings with regard to decision authority in relation to general sickness absence $(15,27-29)$. An earlier analysis of the same data showed that there were also indications for a relationship between low decision authority and the occurrence of neck pain (10).

The workers who reported medium skill discretion had an increased risk of sickness absence due to neck pain. The relationship between low skill discretion and sickness absence due to neck pain was increased, however, not statistically significantly. A reason for not finding a statistically significantly increased risk in our study could be the relatively low power of the study. However, the finding of an univariate statistically significantly increased risk of 4.4 and a multivariate nonstatistically significantly increased risk of 1.6 may be an indication of the existence of a relationship between low skill discretion and sickness absence due to neck pain. Our earlier analysis did not show a relationship between medium and low skill discretion and the occurrence of neck pain (10).

In our present study, the rate ratio for high quantitative job demands in relation to sickness absence due to neck pain was increased, but not statistically significantly. In reports in the literature on the relationship between quantitative job demands and general sickness absence, the results are not consistent. While Kirstensen (27) and Parkes (30) reported that the risk of general sickness absence increases with higher job demands, North et al (28), Smulders \& Nijhuis (29), and Parkes (31) found an inverse effect of high job demands on general sickness absence. If low quantitative job demands were related to the occurrence of neck pain, a statistically significantly increased risk was found (10).

In our present study, low job security was related to an increase in sickness absence due to neck pain, but this relationship was not statistically significant. Low job security was not related to the occurrence of neck pain (10). No reports were found of other studies on the relationship between job security and sickness absence (due to neck pain). Vahtera et al (33) and Kivimäki et al (34) studied the effect of organizational downsizing on general sickness absence. Downsizing, the reduction of personnel in an organization, can be considered a form of job insecurity and is supposed to affect health. In both studies, a statistically significantly relationship was found between organizational downsizing and increased sickness absence. 
For the other work-related psychosocial variables investigated in this study (ie, conflicting job demands, supervisory support, or co-worker support) no clear relationship with sickness absence due to neck pain was found.

According to the demand-control-support model developed by Karasek $(15,35)$, the risk for adverse health effects (eg, sickness absence due to neck pain) is increased in jobs with high demands, low decision latitude, and low workplace support. Because of the relatively low power of the present study, we could not test this hypothesis completely. We have studied only the main effects of these psychosocial variables on sickness absence due to neck pain and did not test the interaction effect between these variables. High quantitative job demands as well as low decision authority and low skill discretion (which together form the dimension decision latitude) were, indeed, related to increased sickness absence due to neck pain. However, neither coworker support nor supervisory support was found to be related to sickness absence due to neck pain.

In our present study, neck pain in the 12 months prior to the beginning of the study was statistically significantly associated with sickness absence due to neck pain. On the basis of the results of their study, Burdorf et al (3) also concluded that complaints of the neck or shoulder in the 12 months prior their study were associated with sickness absence for these complaints during the follow-up period. However, in our present study, neck pain during the 12 months prior to the beginning of the study did not influence the relationship between the work-related physical and psychosocial variables and sickness absence due to neck pain.

\section{Some methodological points}

One strength of our study was the relatively "hard" quality of the sickness absence data (frequency, duration and diagnosis), which had been registered in a standardized way by the participating companies and the occupational health physicians. However, of the 34 companies involved in this study, registrations of sickness absence of 13 companies could not be used in the analysis because there were too many missing entities. For the remaining 21 companies, the diagnoses of sickness absence were sometimes missing, especially for short periods of sickness absence. In everyday practice of Dutch occupational health care, it is very difficult to register the reason for sickness absence if the period of sickness absence lasts only 1 or 2 days. Consequently, in cases of periods of sickness absence lasting only 1 or 2 days, we had many missing values for the variable regarding the reason for sickness absence. We therefore decided to study sickness absence due to neck pain with a mini- mal duration of 3 days. Consequently, we could include 758 workers in the analysis. This number would have been even lower if we had looked at periods of sickness absence shorter than 3 days. Due to the relatively small number of subjects in certain exposure categories, the effect estimates have rather wide $95 \%$ confidence intervals. Despite of these limitations, several statistically significant relationships were found.

\section{Implications for prevention}

The results of our study suggest that decreasing the percentage of time working with the neck flexed or rotated will have a positive effect on the prevention of sickness absence due to neck pain. Increasing a worker's authority over decisions and increasing learning possibilities and the development of skills in a job will probably reduce sickness absence due to neck pain. Moreover, the reduction of job demands (eg, working under time pressure or working with deadlines) will possibly also reduce sickness absence due to neck pain.

The results of our study therefore imply that both adequate workstation design to optimize neck position and organizational changes to increase decision latitude and decrease demands will contribute to the prevention of sickness absence due to neck pain.

\section{Concluding remarks}

1. Working with the neck flexed $>20$ degrees for $>40 \%$ of the worktime and working with the neck flexed $>45$ degrees for $>5 \%$ of the worktime are prospectively and independently related to sickness absence due to neck pain.

2. Working with the neck rotated $>45$ degrees for $>25 \%$ of the worktime is prospectively and independently related to sickness absence due to neck pain.

3. Prolonged sitting at work does not increase sickness absence due to neck pain.

4. Low decision authority and medium skill discretion are prospectively and independently related to sickness absence due to neck pain.

5. There are indications for a relationship between high quantitative job demands, low skill discretion, and low job security with sickness absence due to neck pain.

6. Conflicting job demands, low co-worker support, and low supervisory support are not related to sickness absence due to neck pain.

Scand J Work Environ Health 2002, vol 28, no 4 


\section{Acknowledgments}

This study was financially supported by the Dutch Ministry of Social Affairs and Employment, the Dutch Ministry of Public Health, Welfare and Sports, and the Dutch National Institute of Social Security.

\section{References}

1. Ariëns GAM, Borghouts JAJ, Koes BW. Neck pain. In: Crombie IK, editor. The epidemiology of pain. Seattle (WA): International Association for the Study of Pain Press, 1999: 235-55.

2. Picavet HSJ, Gils HWV van, Schouten JSAG. Klachten van het bewegingsapparaat in de Nederlandse bevolking: prevalenties, consequenties en risicogroepen [Musculoskeletal complaints in the Dutch population: prevalences, consequences and risk groups]. Bilthoven: Rijksinstituut voor Volksgezondheid en Milieu, 2000.

3. Burdorf A, Naaktgeboren B, Post W. Prognostic factors for musculoskeletal sickness absence and return to work among welders and metal workers. Occup Environ Med 1998;55: 490-5.

4. Waersted M, Westgaard RH. Working hours as a risk factor in the development of musculoskeletal complaints. Ergonomics 1991;34:265-76.

5. Borghouts JAJ, Koes BW, Vondeling H, Bouter LM. Costof-illness of neck pain in The Netherlands in 1996. Pain 1999;80:629-36.

6. Ariëns GAM, van Mechelen W, Bongers PM, Bouter LM, van der Wal G. Physical risk factors for neck pain. Scand J Work Environ Health 2000;26:7-19.

7. Ariëns GAM, Van Mechelen W, Bongers PM, Bouter LM, Van der Wal G. Psychosocial risk factors for neck pain: a systematic review. Am J Ind Med 2001;39:180-93.

8. Ganster DC, Schaubroeck J. Work stress and employee health. J Manage 1991;17:235-71.

9. Ariëns GAM, Bongers PM, Douwes M, Miedema MC, Hoogendoorn WE, Van der Wal G et al. Are neck flexion, neck rotation, and sitting at work risk factors for neck pain? Results of a prospective cohort study in an occupational setting. Occup Environ Med 2001;58:200-7.

10. Ariëns GAM, Bongers PM, Hoogendoorn WE, Houtman ILD, Van der Wal G, Van Mechelen W. High quantitative job demands and low co-worker support are risk factors for neck pain: results of a prospective cohort study. Spine 2001; 26:1896-901.

11. Hoogendoorn WE, Bongers PM, De Vet HCW, Douwes M, Koes BW, Miedema MC et al. Flexion and rotation of the trunk and lifting at work are risk factors for low back pain: results of a prospective cohort study. Spine 2000;25:3087-92.

12. Hoogendoorn WE, Bongers PM, de Vet HCW, Houtman ILD, Ariëns GAM, van Mechelen W, et al. Psychosocial work characteristics and psychological strain in relation to low-back pain. Scand J Work Environ Health 2001;27:258-67.

13. De Jonge J, Reuvers MMEN, Houtman ILD, Bongers PM, Kompier MAJ. Linear and nonlinear relations between psychosocial job characteristics, subjective outcomes and sickness absence: Baseline results from SMASH. J Occup Health
Psychol 2000;5:256-68.

14. Karasek RA, Pieper CF, Schwartz JE. Job content questionnaire and user's guide: revision 1. Los Angeles (CA): University of Southern California Los Angeles (USCLA), 1985.

15. Karasek RA. Job demands, job decision latitude, and mental strain: Implications for job redesign. Admin Sci Q 1979;24: 285-308.

16. Johnson JV, Hall E. Job strain, work place social support, and cardiovascular disease. Am J Public Health 1988;78: 1336-42.

17. Gemeenschappelijk Administratiekantoor (GAK). Gedifferentieerd diagnosecode-systeem (GDS) [Differentiated diagnose code system]. Amsterdam: GAK, 1990.

18. World Health Organization (WHO). International classification of disease 1975 revision; vol 1. Geneva: WHO, 1977.

19. Hildebrandt VH, Douwes M. Lichamelijke belasting en arbeid: vragenlijst bewegingsapparaat [Physical load and work: questionnaire on musculoskeletal load and health complaints]. Voorburg: Ministerie van Sociale Zaken en Werkgelegenheid, Directoraat-Generaal van de Arbeid, 1991, S1 22-3.

20. Godin G, Jobin J, Bouillon J. Assessment of leisure time exercise behaviour by self-report: a concurrent validity study. Can J Public Health 1986;77:359-62.

21. Schreurs PJG, Van de Willige G, Tellegen B, Brosschot JF. De Utrechtse Coping Lijst: UCL-handleiding [The Utrecht coping list: UCL manual]. Lisse: Swets \& Zeitlinger, 1988.

22. Hosman $\mathrm{CMH}$. Psychosociale problemen en hulp zoeken [Psychosocial problems and care-seeking]. Lisse: Swets \& Zeitlinger, 1983.

23. McCullagh P, Nelder JA. Generalised linear models. London: Chapman and Hall, 1983:127-40.

24. SAS/STAT user's guide, version 6. Cary (NC): SAS Institute Inc., 1990.

25. Hosmer DW, Lemeshow S. Applied logistic regression. New York (NY): John Wiley \& Sons, 1998:82-134.

26. Ekberg K, Wildhagen I. Long-term sickness absence due to musculoskeletal disorders: the necessary intervention of work conditions. Scand J Rehabil Med 1996;28:39-47.

27. Kristensen TS. Sickness absence and work strain among Danish slaughterhouse workers: an analysis of absence from work regarded as coping behaviour. Soc Sci Med 1991;32:15-27.

28. North FM, Syme SL, Feeney A, Shipley M, Marmot M. Psychosocial work environment and sickness absence among British civil servants: the Whitehall II study. Am J Public Health 1996;86:332-40.

29. Smulders PGW, Nijhuis FJN. The job demands-job control model and absence behaviour: results of a 3-year longitudinal study. Work Stress 1999;13:115-31.

30. Parkes KR. Locus of control as moderator: an explanation for additive versus interactive findings in the demand-discretion model of work stress? Br J Psychol 1991;82:291-312.

31. Parkes KR. Occupational stress among student nurses: a natural experiment. J Appl Psychol 1982;67:784-96.

32. Marmot M, Feeney A, Shipley M, North F, Syme SL. Sickness absence as a measure of health status and functioning: from the UK Whitehall II study. J Epidemiol Community Health $1995 ; 49: 124-30$.

33. Vahtera J, Kivimäki M, Pentti J. Effect of organisational downsizing on health of employees. Lancet 1997;350:1124-28.

34. Kivimäki M, Vahtera J, Pentti J, Ferrie JE. Factors underlying the effect of organisational downsizing on health of 
employees: longitudinal cohort study. BMJ 2000;320:971-5.

35. Karasek RA. Demand/Control model: A social, emotional, and physiological approach to stress risk and active behaviour development. In: Stellman JM, editor. Encyclopedia of occupational health and safety. Geneva: International Labour Office, 1998;34:6-34.

Received for publication: 11 December 2001

\section{Appendix}

Potential confounders of the association between work-related physical and psychosocial variables and sickness absence due to neck pain with a minimal duration of 3 days:

\section{Work-related physical factors}

Number of times lifting $\geq 25 \mathrm{~kg}$ per 8-hour workday (no lifts, at least 1 lift)

Percentage of worktime with $\geq 60$ degrees upper arm elevation $(<5 \%,>5 \%)^{\text {a }}$

Percentage of worktime carrying out repeated movements $>4$ times/minute $(0 \%,>0 \%)$

Video display terminal work (seldom or never, sometimes, often, very often) ${ }^{\text {a }}$

Work with hands above shoulder level (seldom or never, sometimes, often, very often) a

Work with vibrating tools (seldom or never, sometimes, often, very often)

Driving a vehicle (seldom or never, sometimes, often, very often)

Frequent flexion or rotation of upper part of body (seldom or never, sometimes, often, very often)

\section{Nonwork-related physical factors}

Prolonged sitting (seldom or never, sometimes, often, very often)

Video display terminal work (seldom or never, sometimes, often, very often)

Activities with hands above shoulder level (seldom or never, sometimes, often, very often) ${ }^{\text {a }}$

Force exertion with hand or arms (seldom or never, sometimes, often, very often)

Activities in the same posture for a long time (seldom or never, sometimes, often, very often)

Work with vibrating tools (seldom or never, sometimes, often, very often)

Frequent flexion or rotation of upper part of body (seldom or never, sometimes, often, very often) ${ }^{\mathrm{a}}$

Repeated movements with hands or arm many times a minute (seldom or never, sometimes, often, very often)

Driving a vehicle (seldom or never, sometimes, often, very often) ${ }^{a}$

Frequency of sports or heavy physical activities that cause sweating during the past 4 months ( $>3$ times/ month, $1-3$ times/month, $<1$ time/month) a

\section{Individual characteristics}

Gender (male, female)

Age (continuous variable) ${ }^{\text {a }}$

Body mass index $\left(<25,25-30,>30 \mathrm{~kg} / \mathrm{m}^{2}\right)$

Coping: avoidance behavior (low, high)

Coping: social support seeking (low, high)

Coping: active problem solving (low, high) a

Stressful life events in previous 12 months (no stressful life events, at least one stressful life event) ${ }^{\mathrm{a}}$ 